\title{
Water level oscillations in Monterey Bay and Harbor
}

\author{
J. Park ${ }^{1}$, W. V. Sweet ${ }^{2}$, and R. Heitsenrether ${ }^{3}$ \\ ${ }^{1}$ National Park Service, 950 N. Krome Ave, Homestead, FL, USA \\ ${ }^{2}$ NOAA, 1305 East West Hwy, Silver Spring, MD, USA \\ ${ }^{3}$ NOAA, 672 Independence Parkway, Chesapeake, VA, USA
}

Correspondence to: J. Park (joseph_park@nps.gov)

Received: 13 October 2014 - Published in Ocean Sci. Discuss.: 20 November 2014

Revised: 2 May 2015 - Accepted: 12 May 2015 - Published: 8 June 2015

\begin{abstract}
Seiches are normal modes of water bodies responding to geophysical forcings with potential to significantly impact ecology and maritime operations. Analysis of high-frequency $(1 \mathrm{~Hz})$ water level data in Monterey, California, identifies harbor modes between 10 and $120 \mathrm{~s}$ that are attributed to specific geographic features. It is found that modal amplitude modulation arises from cross-modal interaction and that offshore wave energy is a primary driver of these modes. Synchronous coupling between modes is observed to significantly impact dynamic water levels. At lower frequencies with periods between 15 and $60 \mathrm{~min}$, modes are independent of offshore wave energy, yet are continuously present. This is unexpected since seiches normally dissipate after cessation of the driving force, indicating an unknown forcing. Spectral and kinematic estimates of these low-frequency oscillations support the idea that a persistent anticyclonic mesoscale gyre adjacent to the bay is a potential mode driver, while discounting other sources.
\end{abstract}

\section{Introduction}

Bounded physical systems support normal modes. This is true in quantum mechanical, astronomical, and terrestrial systems such as harbors and bays, and owing to the central role that harbors play in human endeavors, there is a rich history analyzing resonant modes of bays and harbors (seiches); see, for example, Darwin (1899), Chrystal (1906) and AMS (1903, 1906).

Monterey Bay, California (Fig. 1), is a dynamic and ecologically rich system influenced by Monterey Submarine Canyon, the California Current, seasonal upwelling, and inshore countercurrents (California undercurrent, David- son current). Monterey Submarine Canyon is the prominent bathymetric feature, where tidally coherent internal waves are nearly an order of magnitude stronger than the open ocean, with the most intense waves characterized as bores (Kunze et al., 2002; Key, 1999; Petruncio et al., 1998), and where hydrodynamic mixing (turbulent kinetic energy dissipation) reaches 3 orders of magnitude greater than the open ocean (Carter and Gregg, 2002). Interaction of the regional coastline and bathymetry with the California Current establishes a persistent anticyclonic mesoscale vortex adjacent to the bay that is readily observed in satellite ocean surface temperature images (Strub et al., 1991; Rosenfeld et al., 1994) and in high-resolution hydrodynamic models (Tseng et al., 2005, 2012; Tseng and Breaker, 2007). For example, Fig. 2 clearly depicts the gyre expressed in sea surface temperatures from satellite thermal imagery. Upwelling driven by local wind forcing interacts with this gyre, resulting in a bifurcated flow of upwelled water with one branch advected northward near Point Año Nuevo just north of the bay, and the other directed equatorward along the outside edge of the bay (Rosenfeld et al., 1994).

The bay supports commercial fishing, diving and marine recreation industries serviced from harbors in Monterey, Moss Landing and Santa Cruz. Water level oscillations in the bay and harbors, along with their associated hydraulic currents, play a significant role in the safety and operation of these interests, and, from an oceanographic perspective, Breaker et al. (2008) have posed an open question regarding the continuous forcing of these modes. That is, seiches are normally excited by transient forcings such as seismic or meteorological events, then tend to lose energy and dissipate; however, modal oscillations in Monterey Bay are observed to be continuously present. Furthermore, Breaker et al. (2010) 


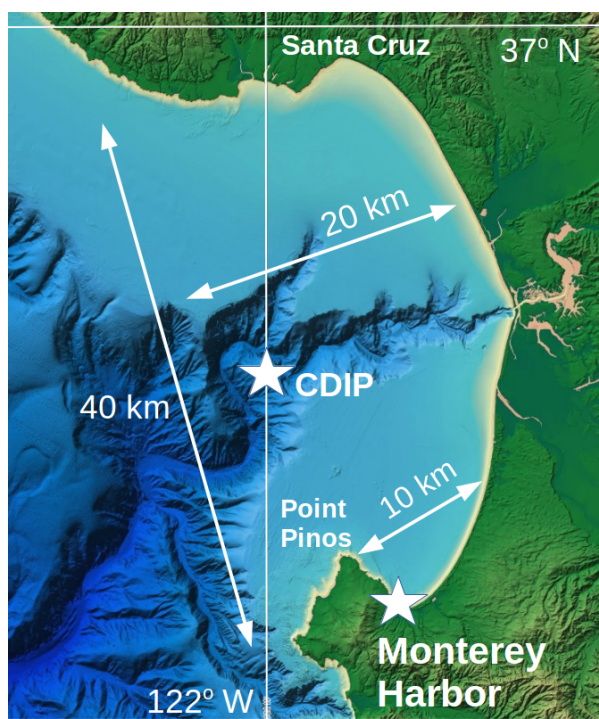

Figure 1. Monterey Bay and Canyon. The location of the wave gauge (CDIP) and water level gauges are indicated with stars. Station information and coordinates for the CDIP buoy are provided in CDIP (2014), and for the tide gauges in NOAA (2014a). We classify bight modes as having periods between 2 and $15 \mathrm{~min}$ with length scales between 2 and $10 \mathrm{~km}$, and bay modes with periods longer than $15 \mathrm{~min}$ and scales from 10 to $40 \mathrm{~km}$.

noted that "it is difficult to conceive that such oscillations occur only in Monterey Bay, and, if it turns out that the excitation is global in nature, then our results may apply to other resonant basins around the world as well". We therefore have two open research questions before us: what is the origin of these continuous modes, and, are they peculiar to Monterey Bay?

The seminal study of bay modes was contributed by Wilson et al. (1965), who applied analytical and numerical models of increasing sophistication to characterize the oscillations. While some of the numerical results were unsatisfying, the breadth and depth of the analysis were pioneering, and many of the fundamental results quantifying bay modes have been corroborated over ensuing decades. Wilson et al. (1965) assumed that "the surge phenomenon in Monterey Harbor is the consequence of surf-beats or of genuine long-period waves", concluding that the latter was likely the cause, and it is notable that previous studies did indicate the continuous presence of oscillations. For example, Forston et al. (1949) analyzed a 6-month wave gauge record and found that $8-22 \mathrm{~s}$ period waves were present nearly $100 \%$ of the time, and Raines (1967) examined a 3-year tide gauge record, finding that "shorter waves (1.5-2 $\mathrm{min})$ are recorded almost continuously"; however, we believe that Breaker et al. (2008) were the first to conclusively observe that long-period bay-wide oscillations are effectively stationary and to question their genesis.

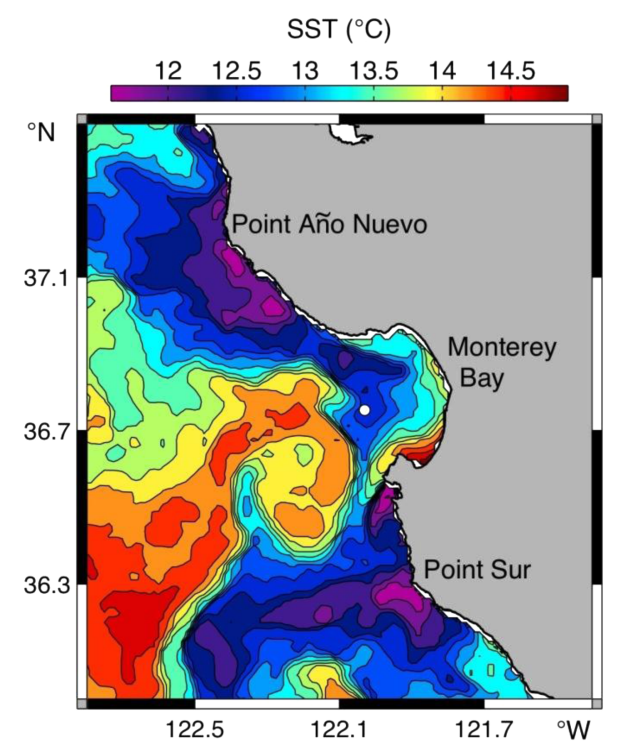

Figure 2. Sea surface temperature image from 13 October 2008 depicting the persistent mesoscale anti-cyclonic gyre offshore of Monterey Bay. Image from Ryan et al. (2014).

Breaker et al. (2010) contributed a comprehensive review and analysis of Monterey Bay oscillations, and based on measurements over an 18 month period determined primary bay modes at the Monterey tide gauge of 55.9, 36.7, 27.4, $21.8,18.4$ and $16.5 \mathrm{~min}$, broadly consistent with the work of Wilson et al. (1965). There is general agreement that the 55.9 min mode represents the fundamental longitudinal mode (north-south), while the 36.7 min harmonic is attributed to the primary transverse mode (east-west; refer to 1). It is also accepted that Monterey Submarine Canyon acts to decouple the bay into two weakly coupled oscillators, one north of the canyon and one south. Regarding Monterey Harbor, estimates of modal periods are more variable, with most sources suggesting periods of $1-2$ to $13.3 \mathrm{~min}$, and several making specific mention of 9-10 min.

Previous observational studies (reviewed in Breaker et al., 2010) used water level data sampled at (or averaged to) daily, hourly, 6, 4 or 1 min intervals such that periods below several minutes are not resolved. Here, we examine a 63 day record of $1 \mathrm{~Hz}$ water level recorded at the National Oceanic and Atmospheric Administration (NOAA) Monterey tide gauge allowing spectral characterization of water level variance to periods as short as $2 \mathrm{~s}$, which to our knowledge is the highestresolution analysis of modal oscillations in the bay. This high-resolution data are used to quantify and attribute water level oscillation modes in Monterey Bay and Harbor to physical processes and boundary conditions. We also analyze a 17.8 year record of $6 \mathrm{~min}$ water levels to characterize modes associated with bay-wide resonances, which to our knowledge is the longest continuous record of water levels analyzed for modal oscillations in the bay. This novel com- 
bination of data allows us to examine potential mode drivers of both harbor and bay-wide oscillations, clarifying the roles of potential mode drivers suggested by Breaker et al. (2010) and suggesting a new one.

\section{Length scales}

The dispersion relation for surface gravity waves dictates length scales corresponding to water depth and oscillation period (resolved from spectral analysis), and we characterize water level oscillations as belonging to bay, bight or harbor modes according to spatial scales appropriate to each domain as shown in Table 1. We define harbor oscillations as modes with periods less than $180 \mathrm{~s}$ and wavelengths less than $1 \mathrm{~km}$ matching spatial scales within the breakwater of Monterey Harbor (Figs. 1 and 5). Modes with periods between 2 and 15 min and length scales between 2 and $10 \mathrm{~km}$ are considered bight modes associated with resonances between Point Pinos at the tip of Monterey Peninsula and the eastern shore of the bay. Bay modes have periods longer than $15 \mathrm{~min}$ and scales from 10 to $40 \mathrm{~km}$. The lowest-frequency bay modes correspond to the longitudinal and transverse lengths of the bay.

\section{Observations}

Observations consist of a 63 day record (14 September through 29 November 2013) of $1 \mathrm{~Hz}$ water level from a microwave ranging sensor at the NOAA tide station located on Monterey Municipal Wharf no. 2, a 17.8 year record of 6 min water levels (23 August 1996-30 June 2014) from an acoustic ranging tide gauge located $4 \mathrm{~m}$ shoreward of the microwave sensor, and offshore wave height estimated every $30 \mathrm{~min}$ over the 63 day record of $1 \mathrm{~Hz}$ data from the Coastal Data Information Program (CDIP) buoy located approximately $15.2 \mathrm{~km}$ WSW of Moss Landing above Monterey Submarine Canyon. Station information and coordinates for the CDIP buoy are provided in CDIP (2014), and for the tide gauges in NOAA (2014a). Gauge locations are shown in Fig. 1 with the white stars.

Since the bay and harbor oscillations are at much higher frequencies than the tides, we remove the tidal signal from the $1 \mathrm{~Hz}$ water level and analyze the water level nontide residual (NTR). The tidal response is obtained from standard NOAA tidal predictions at the Monterey tide gauge derived from 37 harmonic constituents over the tidal datum epoch of 1983 to 2001 (NOAA, 2014b).

Continuous availability of the $1 \mathrm{~Hz}$ data was not achieved, resulting in five segments of lengths 12.1, 12.3, 14.3, 10.5 and 14.1 days as shown in Fig. 3 exhibiting a relationship between nontide residual and offshore wave height. The magnitude of nontide residual is observed to be strongly correlated with wave height, and should be related to the canonical definition of significant wave height $H_{\mathrm{m} 0}=4 \sigma$, where $H_{\mathrm{m} 0}$ is
Table 1. Spatial scales of the bay, bight and harbor modes according to the dispersion relation $\omega^{2}=g k \tanh (k d)$ where $\omega$ is frequency, $k$ the wave number, $d$ the water depth and $\lambda$ the wavelength. The bay and bight modes use depths of $60 \mathrm{~m}$, the harbor modes $7.5 \mathrm{~m}$.

\begin{tabular}{rrrrrr}
\hline \multicolumn{2}{c}{ Bay } & \multicolumn{2}{c}{ Bight } & \multicolumn{2}{c}{ Harbor } \\
Period & $\lambda / 2$ & Period & $\lambda / 2$ & Period & $\lambda / 2$ \\
$(\min )$ & $(\mathrm{km})$ & $(\mathrm{min})$ & $(\mathrm{km})$ & $(\mathrm{s})$ & $(\mathrm{m})$ \\
\hline 55.9 & 40.7 & 10.1 & 7.4 & 112 & 480 \\
36.7 & 26.7 & 9.0 & 6.5 & 60 & 252 \\
27.4 & 19.9 & 4.2 & 3.1 & 41 & 172 \\
21.7 & 15.8 & & & 31 & 133 \\
18.4 & 13.4 & & & 16 & 67 \\
16.5 & 12.0 & & & 12 & 50 \\
\hline
\end{tabular}

the zeroth moment of the water elevation spectrum and $\sigma$ the standard deviation of water level. However, here, the water level variance and the significant wave height are not collocated, and it is known that non-wave-driven processes such as wind-driven setup and local oscillations also contribute to the variance such that the canonical relationship is not expected to be realized. Nonetheless, it is worth noting that water level variance estimates from tide gauges are robustly related to wave height and do have potential as proxies of wave height estimates (Parke and Gill, 1995; IOOS, 2009; Park et al., 2014).

\section{Oscillations in Monterey Harbor}

Figure 4 presents $1 \mathrm{~Hz}$ water level data over 14 days of November 2013, the corresponding spectrogram of a $1 \mathrm{~Hz}$ nontide residual computed with $60 \mathrm{~min}$ windows and $50 \%$ overlap, and a power spectral density (PSD) estimate of the 14 day, $1 \mathrm{~Hz}$ nontide residual. Power spectral densities are estimated by periodogram with a split cosine bell taper and modified Daniell smoother (Bloomfield, 1976). The PSD indicates that dominant harbor energy is found at periods of $112,60,41,31,16$ and $12 \mathrm{~s}$, and are marked with vertical dashed lines. Bight modes are also identified with dash-dot lines (10.1, 9.0 and 4.2 min), and bay modes with dashed lines (55.9, 36.7, 27.4, 21.8, 18.4 and $16.5 \mathrm{~min})$. Bight and bay modes are discussed in a following section.

\subsection{Harbor modes}

Harbor modes are typified by smooth broad peaks in the $\mathrm{PSD}$, suggesting that for a specific harbor component, there are multiple harmonic oscillators closely grouped in wavenumber space, leading us to expect that there will be a nearly continuous range of spatial scales contributing to these modes. In addition to the broad spectral peak centered on $112 \mathrm{~s}$, there are also distinct spectral lines near $112 \mathrm{~s}$ indicating specific resonant scales. The spectrogram reveals a timedependent intensity of harbor modes, for example, the gen- 

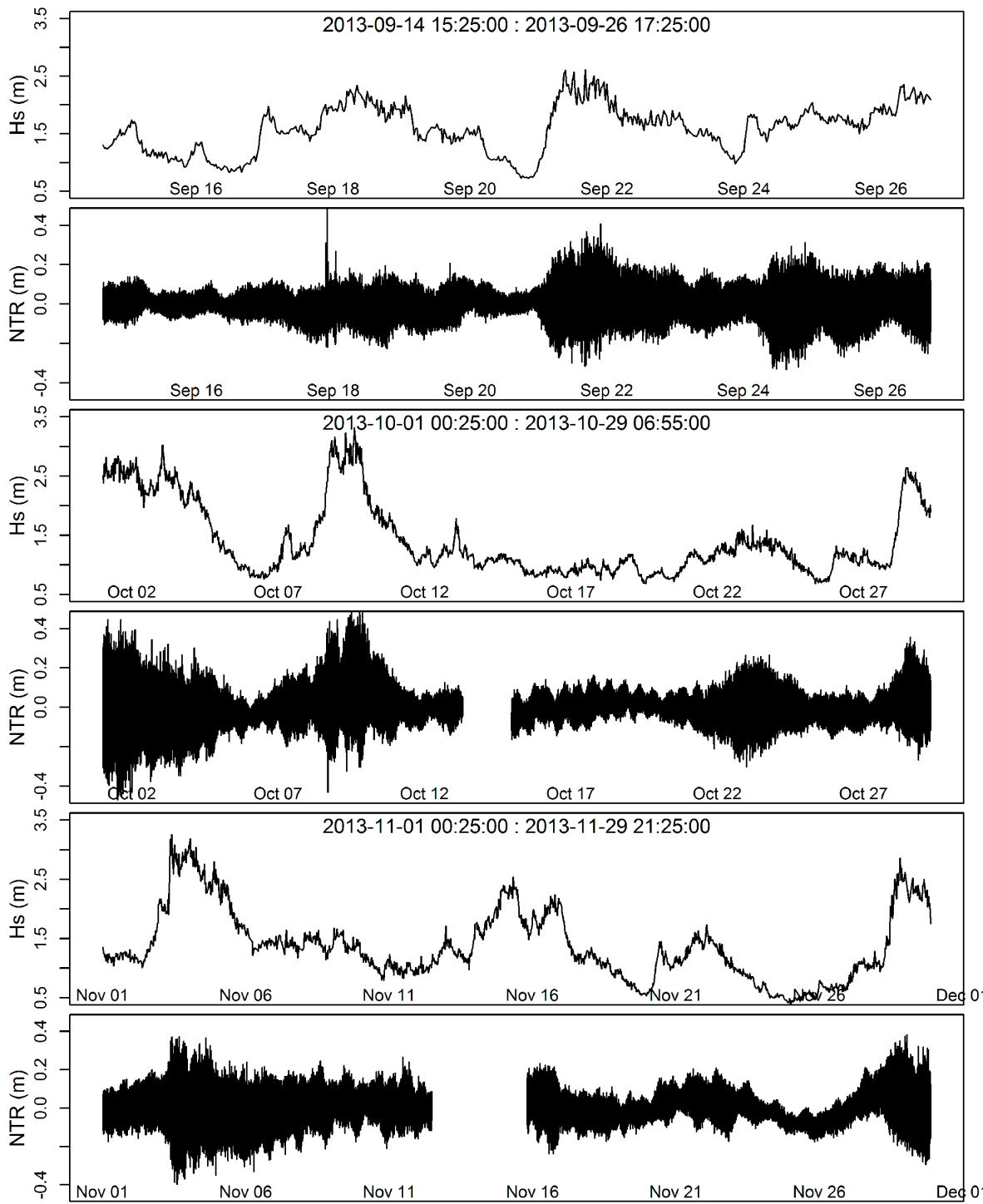

Figure 3. Significant wave height $\left(H_{\mathrm{S}}\right)$ at the Monterey Canyon CDIP buoy (30 min data) and $1 \mathrm{~Hz}$ nontide residual water (NTR) levels from the NOAA tide gauge in Monterey Harbor.

erally low amplitudes around 25 November and high amplitudes following 27 November. Referring to Fig. 3 suggests that offshore wave height influences harbor amplitudes. Another interesting feature is the frequency modulation (FM) of modes coherent with the tidal signal. We believe that this frequency modulation arises from the changing water depth and shoreline profile as mean water level rises and falls such that different length scales for surface waves are realized. These spectral features are representative of all $1 \mathrm{~Hz}$ data.

Figure 5 shows a chart of the harbor with colored arrows corresponding to resonant mode length scales governed by the dispersion relation at a water depth of $7.5 \mathrm{~m}$ from mode periods identified in Fig. 4. The highest-frequency modes with periods less than $30 \mathrm{~s}$ are not depicted in Fig. 5; they are associated with reflections from wharf infrastructure. It should be noted that standing waves form nodes at multiples of $\lambda / 2$ from a reflective fixed boundary, and at multiples of $\lambda / 4$ from an open boundary so that the lowest-frequency standing wave (mode) between two reflectors corresponds to a distance of $\lambda / 2$, and in the case of a mode between an open boundary such as the tide gauge on the wharf and a reflector, a distance of $\lambda / 4$. Given this, we attribute the 30 and $60 \mathrm{~s}$ modes to reflections from the breakwater protecting the mooring docks, the $41 \mathrm{~s}$ mode to a standing wave within the mooring docks, and the dominant harbor mode near $112 \mathrm{~s}$ to reflections between the inner and outer breakwaters. 


\subsection{Wave height}

To assess the wave dependence of harbor mode amplitudes, Fig. 6 presents NTR PSD estimates during three $2 \mathrm{~h}$ periods when offshore wave height was increasing. With a significant wave height of $0.8 \mathrm{~m}$ (dominant period $T_{\mathrm{s}}=5.9 \mathrm{~s}$ ), the characteristic harbor modes are broadly observed with the $60 \mathrm{~s}$ period reflection from the breakwater well resolved. As significant wave height grows from 0.8 to $1.1 \mathrm{~m}$, most of the energy increase is contained in the band between 80 and $300 \mathrm{~s}$, suggesting that it is a combination of growing reflections from the rocky shore to the west, the breakwater to the north and a bight mode contributing to increased NTR variance. When offshore wave height reaches $2.4 \mathrm{~m}\left(T_{\mathrm{s}}=12.5 \mathrm{~s}\right)$, there is a significant increase in energy at all modes, and a conspicuous broadening of the 80 to $120 \mathrm{~s}$ resonances suggesting that a rich set of closely spaced modes is being driven. We also note that spectral shapes are essentially invariant as offshore waves transition from periods of 6 to $12 \mathrm{~s}$ but the amplitudes increase, indicating that these modes are generated by local resonances in the harbor forced by offshore wave energy, but independent of wave period.

To quantify the amplitude dependence of offshore wave height on harbor and bay oscillations, we regress PSD amplitudes of the dominant harbor and bay modes (112 s and $36.7 \mathrm{~min}$, respectively) against offshore significant wave height $\left(H_{\mathrm{s}}\right)$ :

$\mathrm{PSD}_{\mathrm{M}}=\alpha H_{\mathrm{s}}+\beta H_{\mathrm{s}}^{1 / 2}$,

where PSD $_{M}$ are $1 \mathrm{~Hz}$ NTR PSD amplitudes in $\mathrm{dB}$ of the $36.7 \mathrm{~min}$ or $112 \mathrm{~s}$ modes over a $24 \mathrm{~h}$ sliding window advanced in $2 \mathrm{~h}$ increments over all data. Figure 7 plots the data and model fits, indicating that the harbor mode responds to offshore wave amplitude with nonlinear growth $\left(r^{2}=0.70\right)$, while the bay mode has no such dependence $\left(r^{2}=0.03\right)$.

\subsection{Wave direction}

To examine offshore wave direction in the forcing of harbor modes, Fig. 8a plots NTR PSD estimates from two periods when offshore significant wave heights were small $(0.5-0.7 \mathrm{~m})$, and the dominant wave direction was either west $\left(250^{\circ} \mathrm{N}\right)$ or northwest $\left(295^{\circ} \mathrm{N}\right)$. With the exception of the $15 \mathrm{~s}$ resonance, harbor modes are significantly enhanced when low-amplitude waves are arriving from the northwest instead of the west. This is consistent with the wave refraction analysis presented by Wilson et al. (1965) indicating that wave energy from the west is less efficiently refracted into the harbor than waves from the northwest.

Figure $8 \mathrm{~b}$ presents NTR PSD estimates from larger waves and arrival directions of west $\left(265^{\circ} \mathrm{N}\right)$ and northwest $\left(297^{\circ} \mathrm{N}\right)$. Here, a comparison of the NTR spectra finds that wave direction has a smaller influence on harbor mode amplitudes then when waves are small, although some specific modes such as those with 9 and $60 \mathrm{~s}$ periods are enhanced.
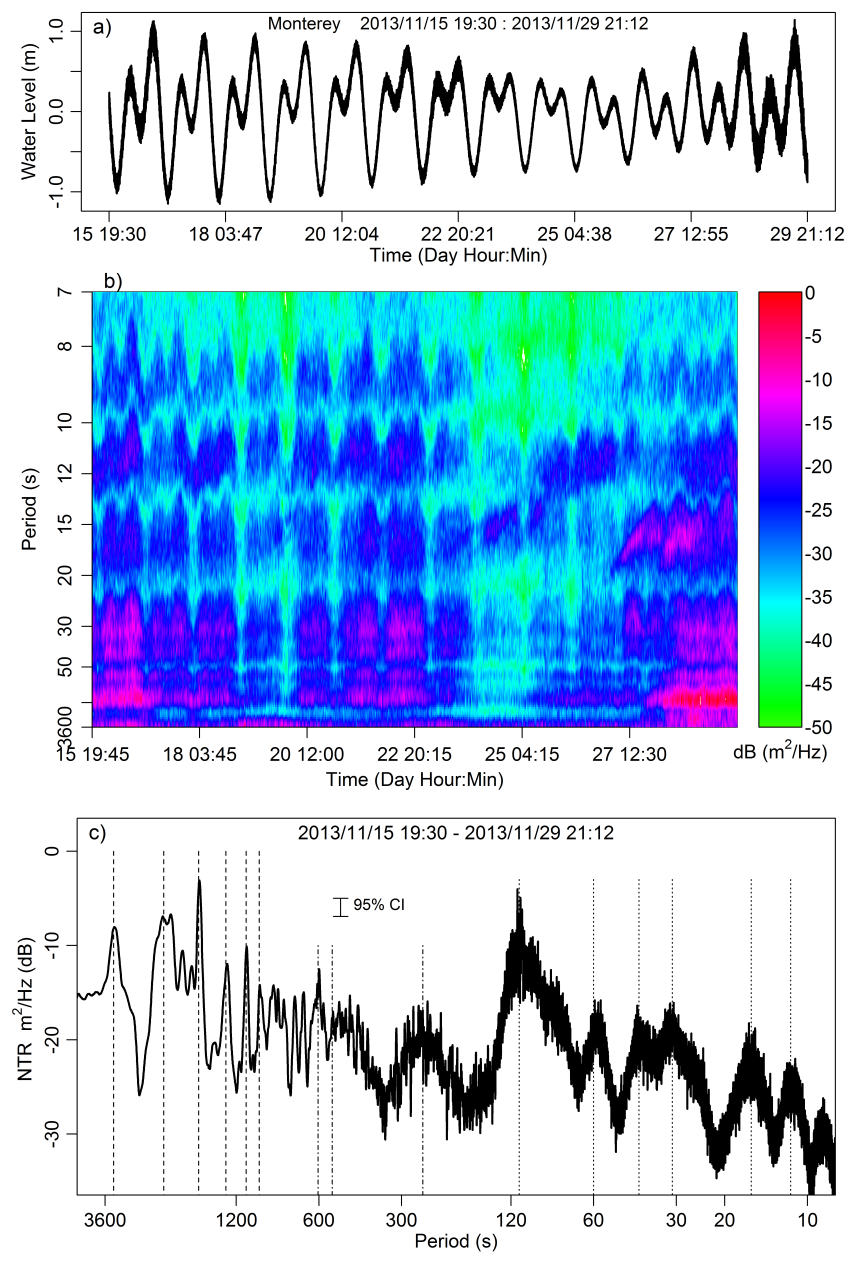

Figure 4. (a) Raw $1 \mathrm{~Hz}$ water levels from 15 November 2013 through 29 November 2013. (b) Spectrogram of the water levels. (c) Power spectral density estimates of nontide residual water levels. Dashed vertical lines mark the bay-wide resonance modes (55.9, $36.7,27.4,21.8,18.5$ and $16.5 \mathrm{~min})$, dash-dot lines mark bight periods (10.1, 9.0 and 4.2 min) and dotted lines the harbor modes (112, $60,41,31,16$ and $12 \mathrm{~s})$.

\subsection{Tidal phase}

Spectrograms of $1 \mathrm{~Hz}$ data indicate that tidal phase serves to modulate the frequency of harbor modes as shown in Fig. 4b. To examine this, we selected a period with minimum offshore wave height covering a semidiurnal tidal cycle (25 November, 04:30 to 14:00 UTC). This cycle corresponds to the largest semidiurnal cycle of the day with a range of roughly $1 \mathrm{~m}$, which is close to the mean tidal range of $1.08 \mathrm{~m}$. The water depth at the sensor is nominally $9.1 \mathrm{~m}$ at MLLW, so that the water depth to mean tidal range ratio is roughly 9 to 1 .

To compare the spectral response of these two tidal regimes, we computed NTR PSD estimates over $2 \mathrm{~h}$ periods centered on the low (04:30-06:30) and high water (12:00- 


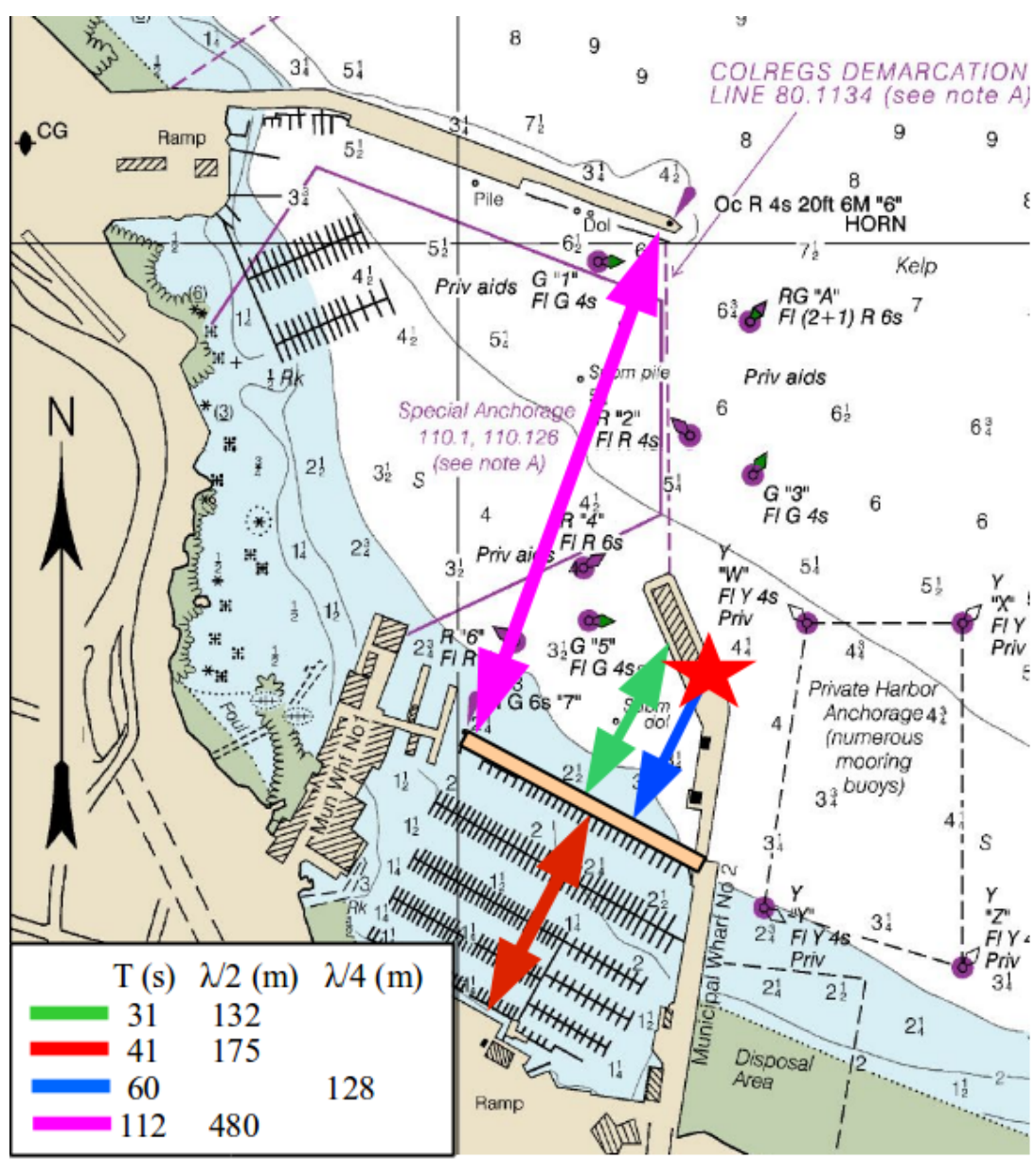

Figure 5. Chart of Monterey Harbor with resonant mode length scales corresponding to periods observed in the power spectra. The tide gauge location is denoted by the star. Wavelengths are determined from the general dispersion relation applied at a depth of $7.5 \mathrm{~m}$. Spatial scales of $\lambda / 2$ are sustained between two reflective boundaries, while the fundamental length of $\lambda / 4$ corresponds to one open boundary such as the tide gauge on the wharf and one reflective boundary. Chart is number 18685 from the NOAA National Ocean Service Coast Survey.

14:00) tidal phases as shown in Fig. 9. There is a clear shift from longer to shorter periods at high water in relation to low water, supporting the idea that water depth and associated shoreline boundary condition characteristics influence the modal structure of the harbor.

We note that this cycle was during a neap tide, and expect that, during spring tide, the tidal dependence on harbor oscillation frequencies will be even more pronounced. For example, in Fig. 4b, we noted the frequency modulation of harbor modes with tidal phase where the tidal range exceeded $2 \mathrm{~m}$, and one can clearly see the changing frequencies of the harbor modes.

\subsection{Dynamic mode response}

The dynamic characteristics of harbor modes can be assessed by decomposing the $1 \mathrm{~Hz}$ nontide residuals into components capturing temporal variations at different timescales with a maximal overlap discrete wavelet transform (MODWT,
Percival and Walden, 2006). The MODWT is defined in Appendix A and we employ an 11-level $(J=11)$ transform based on the least asymmetric mother wavelet (LA8). Approximate temporal scales for the wavelet levels are listed in Table 2.

Figure 10 plots the MODWT decomposition for two of the $2 \mathrm{~h}$ periods shown in Fig. 6 . The bottom panel of each plot shows the NTR time series with panels above in ascending order plotting the wavelet coefficients for each level of increasing timescale. The wavelet coefficients of each level are scaled by their respective magnitude squared so that the amplitude represents the partial variance contributed by each level. With offshore significant wave heights of $0.8 \mathrm{~m}(0$ $2000 \mathrm{~s}$ in Fig. 10a), the NTR energy is fairly evenly distributed between the $\mathrm{W}_{3}, \mathrm{~W}_{4}, \mathrm{~W}_{5}, \mathrm{~W}_{6}, \mathrm{~W}_{10}$ and $\mathrm{W}_{11}$ levels corresponding to temporal scales of $15,31,59,99,900$ and $1800 \mathrm{~s}$. As waves grow from 0.8 to $1.1 \mathrm{~m}(3000-7000 \mathrm{~s}$ in Fig. 10a), the $W_{6}$ and $W_{7}$ levels exhibit the emergence of oscillatory modes at timescales of 96 and $126 \mathrm{~s}$, consistent with 


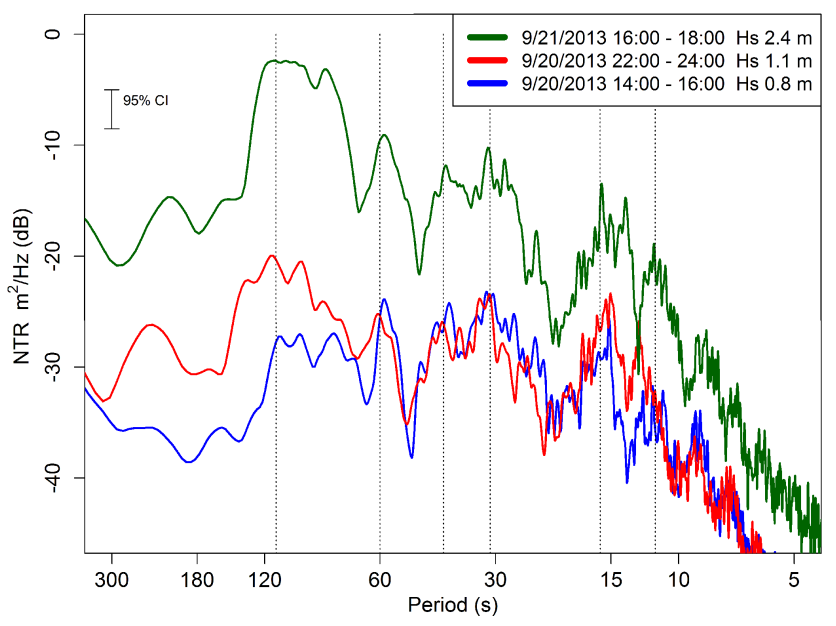

Figure 6. Power spectral density estimates of $1 \mathrm{~Hz}$ nontide residual over $2 \mathrm{~h}$ periods during 20 and 21 September 2013 with different deep water wave heights. Dotted vertical lines mark the harbor modes at $112,60,41,31,16$ and $12 \mathrm{~s}$.
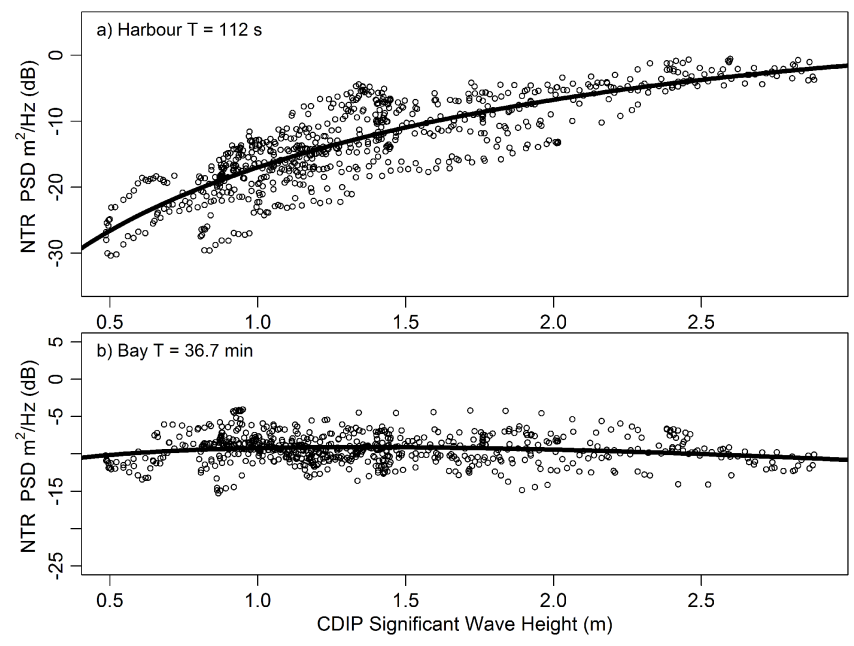

Figure 7. (a) Water level amplitudes at the dominant harbor period of $112 \mathrm{~s}$, and (b) amplitudes at the dominant bay period of $36.7 \mathrm{~min}$ as a function of significant wave height. Each amplitude is estimated from a PSD computed over an $18 \mathrm{~h}$ moving window with a time increment of $1 \mathrm{~h}$. Solid lines are a least squares fit to a nonlinear model $\left(\mathrm{PSD}_{\mathrm{M}}=\alpha H_{\mathrm{S}}+\beta H_{\mathrm{S}}^{1 / 2}\right)$. Note that the water level amplitudes are in $\mathrm{dB}$.

the spectral perspective shown in Fig. 6. When waves have grown to $2.4 \mathrm{~m}$, we find in Fig. $10 \mathrm{~b}$ that the $\mathrm{W}_{5}, \mathrm{~W}_{6}$ and $\mathrm{W}_{7}$ timescales $(58,101,117 \mathrm{~s})$ dominate the NTR energy, again consistent with the Fourier decomposition in Fig. 6. The same general behavior with the emergence, growth and dominance of the 50 to $120 \mathrm{~s}$ modes in Monterey Harbor during wave events is robustly observed.

An interesting feature of these primary harbor modes $\left(\mathrm{W}_{5}\right.$, $\mathrm{W}_{6}$ and $\mathrm{W}_{7}$ ) is their temporal amplitude modulation (AM). These AM effects are generally not synchronous across lev-
Table 2. Wavelet level dominant periods in seconds.

\begin{tabular}{lrrr}
\hline Level & $9 / 2022: 00-$ & $9 / 2116: 00-$ & $10 / 410: 00-$ \\
& $-24: 00$ UTC & $-18: 00$ UTC & $-12: 00$ UTC \\
& $H_{\mathrm{S}} 0.8-1.1(\mathrm{~m})$ & $H_{\mathrm{S}} 2.4(\mathrm{~m})$ & $H_{\mathrm{S}} 2.0(\mathrm{~m})$ \\
\hline W2 & 13 & 12 & 9 \\
W3 & 15 & 14 & 12 \\
W4 & 31 & 31 & 30 \\
W5 & 60 & 58 & 61 \\
W6 & 96 & 101 & 111 \\
W7 & 126 & 117 & 118 \\
W8 & 486 & 405 & 260 \\
W9 & 729 & 663 & 911 \\
W10 & 800 & 830 & 800 \\
W11 & 1030 & 1090 & 1285 \\
\hline
\end{tabular}

els, and appear to have modulation periods in the neighborhood of $20 \mathrm{~min}$. These periods are not representative of the bay or bight modes previously identified, and their nonsynchronous nature suggests that they are not forced by a unitary driver, e.g., long-period waves propagating from offshore. However, we previously noted the broad spectral nature of the harbor modes indicative of multiple harmonic oscillators closely spaced in frequency/wave number, and this leads us to speculate that the AM arises from superposition of closely spaced modes in frequency space. To test this hypothesis, we select 10 spectral amplitudes from the NTR PSD with $2.4 \mathrm{~m}$ wave height from Fig. 6 at periods of 58, 83, 94, $97,100,104,107,112116$ and 209 s, and create a reconstruction from these components with a harmonic superposition:

$R=\sum_{i} A_{i} \sin \left(\omega_{i} t\right)$

where $A_{i}$ is the NTR spectral amplitude and $\omega_{i}$ the frequency. This reconstruction is compared to the $\mathrm{W}_{6}$ level in Fig. 11 where the envelope has been plotted for each time series. Qualitatively, the overall AM behavior of the reconstructed superposition and the actual mode is similar, leading to the suggestion that it is cross-modal interference of closely spaced harbor modes resulting in the AM of specific resonances. Although the AM envelopes are generally not synchronous, there is nothing precluding them from randomly aligning, and in Fig. 12 we present evidence of such an alignment between the $\mathrm{W}_{6}$ and $\mathrm{W}_{7}$ levels suggesting that when modes synchronize, their impact on the overall NTR can be significant.

\section{Oscillations in Monterey Bay}

The bay modes are clearly identified in $1 \mathrm{~Hz}$ spectra (Fig. 4) and we estimate their water level amplitudes over the 63 day period by computing mean PSD amplitudes over all $1 \mathrm{~Hz}$ data over a sliding window of $24 \mathrm{~h}$ advanced in $2 \mathrm{~h}$ increments. The modes are ranked in terms of decreasing amplitude in 
Table 3. Mean water level spectral amplitudes at the bay-wide oscillation modes estimated from $1 \mathrm{~Hz}$ nontide residuals over 63 days. The $95 \%$ confidence interval on spectral amplitude is $3.0 \mathrm{~dB}$.

\begin{tabular}{rrrr}
\hline $\begin{array}{r}\text { Period } \\
(\mathrm{min})\end{array}$ & $\begin{array}{r}\text { PSD dB } \\
\left(\mathrm{m}^{2} \mathrm{~Hz}^{-1}\right)\end{array}$ & $\begin{array}{r}\Delta \mathrm{dB} \\
\left(\mathrm{m}^{2} \mathrm{~Hz}^{-1}\right)\end{array}$ & $\begin{array}{r}\text { Water level } \\
(\mathrm{m})\end{array}$ \\
\hline 36.7 & -9.3 & 0.0 & 0.341 \\
27.4 & -12.8 & -3.4 & 0.230 \\
55.9 & -13.3 & -4.0 & 0.215 \\
21.7 & -15.7 & -6.4 & 0.164 \\
18.4 & -17.8 & -8.4 & 0.129 \\
16.5 & -17.9 & -8.5 & 0.128 \\
\hline
\end{tabular}

Table 3 indicating that the 36.7 min mode exhibits the highest average power. Improved spectral resolution is afforded by a longer record and Fig. 13 presents a spectrogram and PSD of a 17.8 year record of 6 min water level data. Spectrogram PSDs are from records of 2048 points (8.53 days) with $50 \%$ overlap. The two dominant features are the annual occurrence of increased broadband variance from winter storms (vertical bands), and the continuously present energy at the bay periods quantified by Breaker et al. (2010).

The PSD reveals that the 36.7 min transverse bay mode (east-west) is not only the most energetic, but is actually also a series of closely spaced modes. The 27.4 min mode exhibits a high quality $(Q)$ factor (ratio of energy stored in the mode resonance to energy supplied driving the resonance) as evidenced by the high signal-to-noise ratio and narrow bandwidth of the spectral peak indicating a resonance highly tuned to the source. According to Breaker et al. (2010) and Wilson et al. (1965) the spatial harmonics of this mode correspond to partitioning of the bay into thirds with northern, central (canyon) and southern regions, which would suggest that this mode is efficiently tuned to the decoupling of the southern and northern parts of the bay by the canyon, whereas the fundamental longitudinal mode $(55.9 \mathrm{~min})$ is not. It is not clear why this would be the case. The dominance of these modes suggests that they are the modes most directly coupled to the unknown continuous forcing of bay oscillations.

\subsection{Mode forcing}

Breaker et al. (2010) considered six physical mechanisms as prospective forcings for continuous oscillations of the bay:

1. edge waves,

2. long-period surface waves,

3. sea breeze,

4. internal waves,

5. microseisms, and

6. small-scale turbulence,
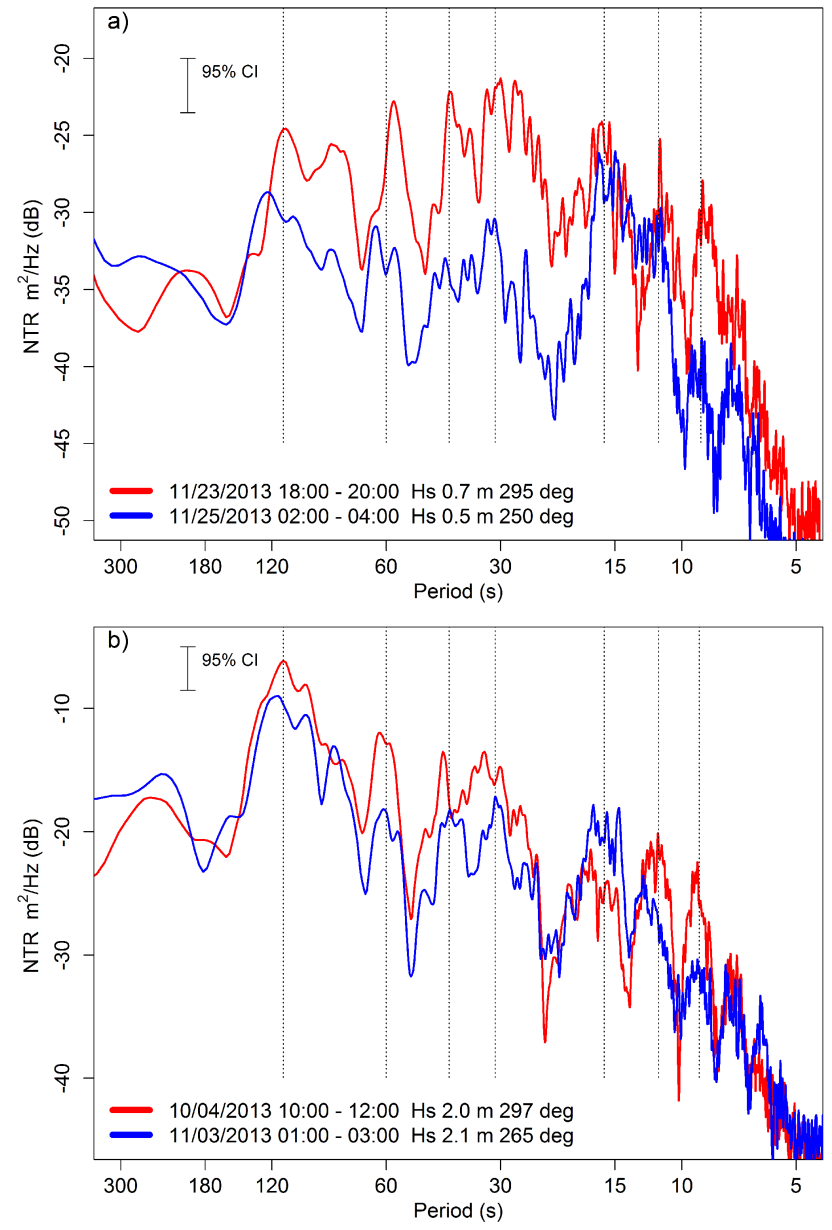

Figure 8. (a) Power spectral density estimates of $1 \mathrm{~Hz}$ nontide residual water level over $2 \mathrm{~h}$ periods with offshore significant wave heights of 0.5 and $0.7 \mathrm{~m}$ and arrival directions of 250 and $295^{\circ}$. (b) Power spectral density estimates of $1 \mathrm{~Hz}$ nontide residual water level over $2 \mathrm{~h}$ periods with offshore significant wave heights of 2.0 and $2.1 \mathrm{~m}$ and arrival directions of 265 and $297^{\circ}$. Dotted lines correspond to harbor modes (112, 60, 41, 31, 16 and $9 \mathrm{~s})$.

and noted that the first three are not likely to be continuously present, and so are not consistent with the observation of persistent oscillations. Tidally synchronous internal waves have been observed propagating up the submarine canyon and episodically transitioning to bores (Key, 1999; Kunze et al., 2002; Carter and Gregg, 2002); their tidal coupling suggests a continuous presence and potential mode forcing. Microseisms are an appealing candidate due to their omnipresence (Kedar et al., 2008); however, it was speculated that their energy was insufficient at the bay frequencies to drive the oscillations. Breaker et al. (2010) also discounted small-scale turbulence on the basis of its intermittent nature. These arguments are based primarily on temporal persistence; however, we offer an alternative perspective based on kinematic energy scales. 


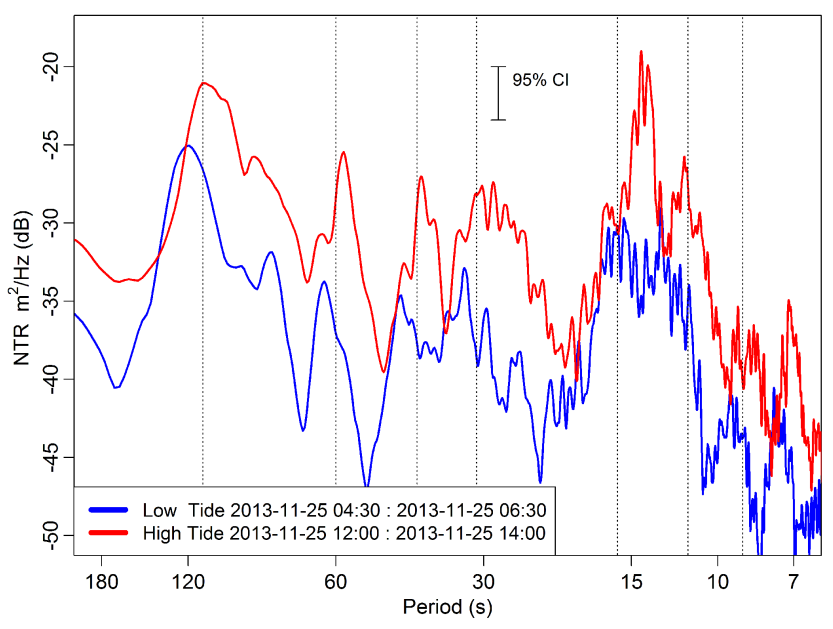

Figure 9. PSD estimates of $1 \mathrm{~Hz}$ NTR data from $2 \mathrm{~h}$ periods centered on low and high water of a tidal period. Offshore waves were low during this period. Dotted vertical lines mark harbor modes at $112,60,41,31,16$ and $12 \mathrm{~s}$.

Under the assumption that the 36.7 min mode is the directly forced fundamental mode, we can ask questions regarding its observed amplitude and spectral resonance to grossly estimate the energy required to sustain it. Table 3 indicates that the rms (root mean square) water level deviation of this mode at the Monterey tide gauge is $h_{\mathrm{M}}=0.341 \mathrm{~m}$. Neglecting the effect of shoaling on wavelength, a raisedcosine profile with $\lambda / 2=26.7 \mathrm{~km}$ (Table 1) approximates the cross-shore elevation of the mode, with a profile area of $A_{\mathrm{M}}=9104 \mathrm{~m}^{2}$. Breaker et al. (2010) assessed spatial harmonics of bay modes with a regional ocean modeling system (ROMS) implementation (Shchepetkin and McWilliams, 2005) providing an estimate of the alongshore profile of this mode. They found a strong harmonic response over the majority of the eastern bay shoreline with a damped response in an area north of the submarine canyon. Based on this, we estimate that approximately $70 \%$ of the shoreline responds to this mode. In the spirit of our gross estimate, we assume the alongshore spatial dimension of the mode to be $L_{\mathrm{A}} \approx 0.7 \times 40 \mathrm{~km}=28 \mathrm{~km}$. Combining this with the crossshore elevation area, we arrive at an estimate of the volume of water displaced by this mode of $V_{\mathrm{M}}=L_{\mathrm{A}} A_{\mathrm{M}} \approx 258 \mathrm{Mm}^{3}$. The energy to move this mass is equivalent to the work performed to change the potential energy of the mass in the gravitational field, and we estimate the energy of the mode as $E_{\mathrm{M}}=\rho V_{\mathrm{M}} h_{\mathrm{M}} g \approx 894.75 \mathrm{GJ}$, or an average power of $406 \mathrm{MW}$ over the $36.7 \mathrm{~min}$ modal period. Obviously, this leading-order value does not incorporate dissipation and momentum, terms that we ignore in all subsequent energy estimates.

If the $Q$ factor is large (the resonance signal-to-noise ratio is high), then $Q$ may be estimated from the power spectrum: $Q=f_{\mathrm{M}} / \Delta f$, where $f_{\mathrm{M}}$ is the mode resonant frequency and
$\Delta f$ the $-3 \mathrm{~dB}$ (half power) bandwidth of the mode. We observe signal-to-noise ratios routinely exceeding $5 \mathrm{~dB}$ at the bay modes (Figs. 4 and 13) and use PSD estimates based on $120 \mathrm{~h}$ records of $1 \mathrm{~Hz}$ NTR $(95 \% \mathrm{CI} 2.6 \mathrm{~dB})$ advanced in $4 \mathrm{~h}$ increments to find a mean $\Delta f=5.86 \times 10^{-5} \mathrm{~Hz}$ and an estimate of $Q=7.74$ for the 36.7 min mode. This implies that within the gross level of estimation in which we are engaged, the driving energy for the $36.7 \mathrm{~min}$ mode is roughly $894.75 / 7.75 \approx 115.5 \mathrm{GJ}$, or a power consumption of 52.4 MW. We will compare this forcing to estimates of energy available from prospective mode drivers in the following sections.

\subsubsection{Microseisms}

Microseisms are pressure (acoustic) waves primarily generated by nonlinear wave-wave interactions on the ocean surface. They radiate into the atmosphere where they are globally detected as microbaroms (Waxler and Gilbert, 2006), into the water column as acoustic modes, and couple into the seafloor where they travel as Rayleigh/Stoneley waves presenting a global seismic signature (Webb and Cox, 1986). One can estimate deep water microseismic energy by considering the acoustic intensity of a plane wave incident on the seafloor $I_{\mathrm{A}}=P^{2} / Z$ where $P$ is the pressure and $Z$ the acoustic impedance. In the linear regime, the characteristic acoustic impedance of a medium is $Z_{0}=\rho c$ where $\rho$ is the density and $c$ the sound speed, which in the case of seawater is approximately $Z_{0} \approx 1.5 \times 10^{6} \mathrm{~N} \mathrm{~s} \mathrm{~m}^{-3}$. Spectral amplitudes of the microseism peak at deep water seafloor sites were found by Webb and Cox (1986) to be approximately $5000 \mathrm{~Pa}^{2} \mathrm{~Hz}^{-1}$, giving an intensity of $I_{\mathrm{A}} \approx 5 \times 10^{-3} \mathrm{~W} \mathrm{~m}^{-2}$. Assuming a source generation region of radius $100 \mathrm{~km}$, the total power is $157 \mathrm{MW}$.

This energy is efficiently converted into seismic Rayleigh waves or ocean acoustic modes (Hasselmann, 1963), and these waves can propagate with small attenuation coefficients over large distances, suggesting that microseismic energy is of sufficient magnitude to couple to bay resonances. However, Bromirski and Duennebier (2002) demonstrate that coastal zone microseismic energy is dominated by local wave reflections from coasts, not deep water arrivals, as propagation from deep to shallow water is inhibited by the changing seismic waveguide as refraction of the Rayleigh modes significantly reduces energy reaching the coastal zone (Hasselmann, 1963). Bromirski and Duennebier (2002) found coastal zone pressures of approximately $70 \mathrm{~Pa}^{2} \mathrm{~Hz}^{-1}$, which under the same assumptions as the deep water case gives a total power of $2.2 \mathrm{MW}$, insufficient to drive the fundamental bay mode. Not only is the estimated energy insufficient, microseismic energy is distributed around periods of 5 to $7 \mathrm{~s}$, more than 2 orders of magnitude shorter than the dominant bay mode, and we conclude that microseisms are not a likely driving mechanism for the continuous bay oscillations. 

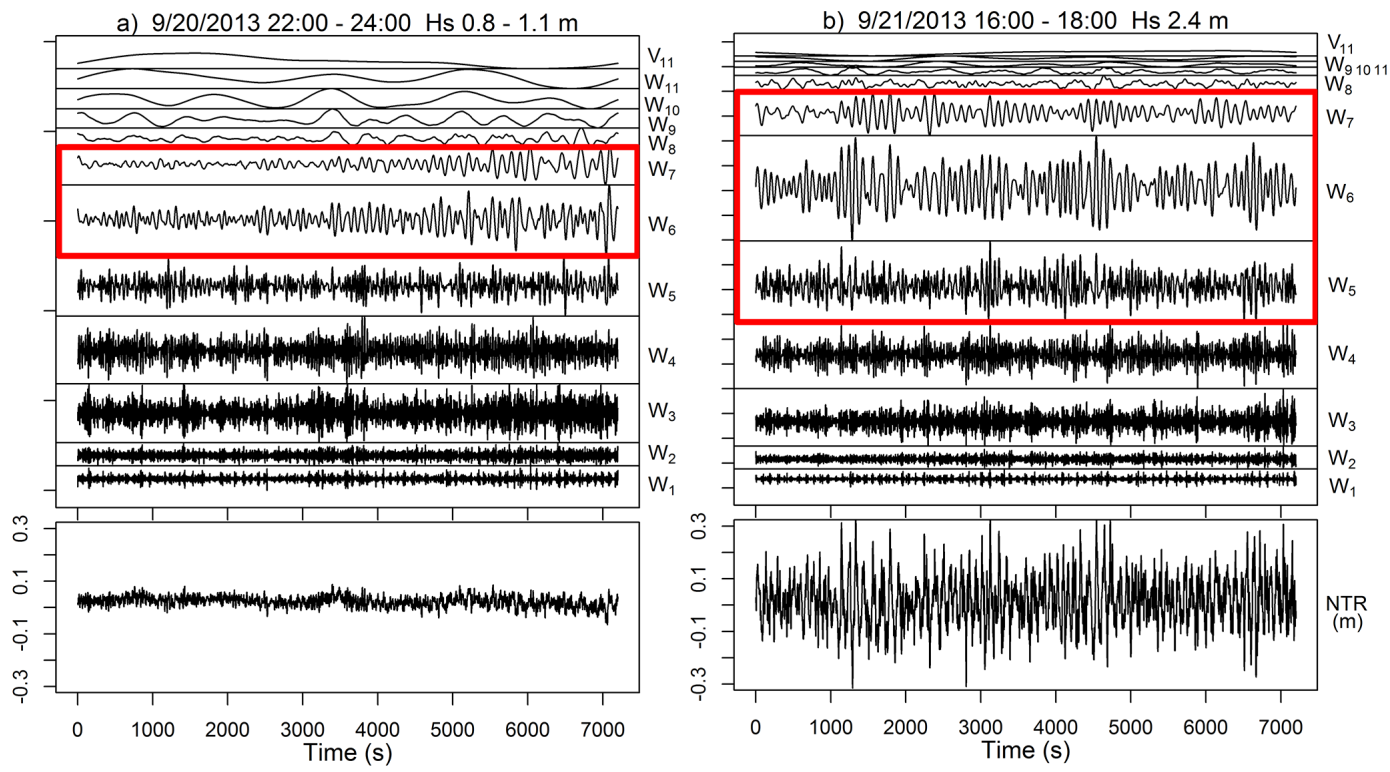

Figure 10. (a) Discrete wavelet transform decomposition of nontide residual during a $2 \mathrm{~h}$ period when deep water significant wave height increased from 0.8 to $1.1 \mathrm{~m}$. The red box highlights the $\mathrm{W}_{6}$ and $\mathrm{W}_{7}$ wavelet levels exhibiting emergence of energy in these two bands as wave height increases. (b) Discrete wavelet transform decomposition of nontide residual during a $2 \mathrm{~h}$ period when deep water significant wave height was $2.4 \mathrm{~m}$. The red box highlights the $\mathrm{W}_{5}, \mathrm{~W}_{6}$ and $\mathrm{W}_{7}$ wavelet levels exhibiting dominance of energy in these bands and amplitude modulation. Power spectral density estimates of these $2 \mathrm{~h}$ period are shown in Fig. 6.

\subsubsection{Internal waves}

Kunze et al. (2002) observed that internal waves in Monterey Canyon are nearly an order of magnitude more energetic than in the open ocean and are tidally locked to $M_{2}$. Mean horizontal energy fluxes are steered by canyon bathymetry and are predominantly up canyon, with depth integrated fluxes of $5 \mathrm{~kW} \mathrm{~m}^{-1}$ at the mouth diminishing to $\pm 1 \mathrm{~kW} \mathrm{~m}^{-1}$ near the head (Moss Landing), although the internal wave field is highly anisotropic, with evidence of both sources and sinks along the canyon. Particularly energetic fluxes have been characterized as bores with peak currents of $55 \mathrm{cms}^{-1}$ and $2 \mathrm{~h}$ averages exceeding $30 \mathrm{cms}^{-1}$ (Key, 1999). Carter and Gregg (2002) quantified turbulent kinetic energy dissipation, finding that the turbulence is primarily in a stratified turbulent layer (STL) along the canyon floor and is thickest on the canyon axis. Time averaged values of STL thickness and dissipation were estimated to be $135 \mathrm{~m}$ and $\bar{\varepsilon}=1.36 \times 10^{-6} \mathrm{~W} \mathrm{~kg}^{-1}$.

Both Kunze et al. (2002) and Carter and Gregg (2002) compared mean internal wave energy flux with dissipation rates, tentatively concluding that most of the along-canyon internal energy is dissipated as turbulence, although Carter and Gregg (2002) noted that "large error estimates suggest this agreement is fortuitous". A gross estimate of the internal tide energy can be made from a mean value of energy flux: $2 \mathrm{~kW} \mathrm{~m}^{-1}$ (Kunze et al., 2002), which for a $20 \mathrm{~km}$ length of canyon gives $P_{\mathrm{I}} \approx 40 \mathrm{MW}(20 \mathrm{~km}$ corresponds to the length of the canyon from the head over which there is a primarily a single channel, is approximately equal to the length of the primary transverse mode, and is the length used by Carter and Gregg (2002) in their global estimates of canyon dissipation). An estimate of the dissipation over this $20 \mathrm{~km} \mathrm{sec-}$ tion with a mean STL height of $135 \mathrm{~m}$ and width of $4 \mathrm{~km}$ $\left(V_{\mathrm{STL}}=10.8 \mathrm{Gm}^{3}\right)$ gives $P_{\mathrm{T}}=\rho V_{\mathrm{STL}} \bar{\varepsilon} \approx 15.1 \mathrm{MW}$.

Even if these gross estimates of internal wave energy and dissipation, which ignore the well-documented fine-scale sink/source and spatial variability, are only accurate to a factor of 2 , the residual energy rate $P_{\mathrm{I}}-P_{\mathrm{T}}=40-15=25 \mathrm{MW}$ is insufficient to sustain our estimate of the fundamental mode (52.4 MW).

\subsubsection{Mesoscale eddy}

A potential energy source that, to the authors knowledge, has not been considered as a mode driver, is the persistent mesoscale anticyclonic gyre offshore Monterey Bay (Fig. 2). The gyre is nominally $50-70 \mathrm{~km}$ in diameter and models suggest that it extends from the surface to at least $600 \mathrm{~m}$ in depth with instantaneous velocities of $70 \mathrm{~cm} \mathrm{~s}^{-1}$ near the surface and $30 \mathrm{cms}^{-1}$ at depth (Tseng and Breaker, 2007; Tseng et al., 2012). The gyre supports a persistent elevated dome of sea surface height (SSH) rising approximately $10-12 \mathrm{~cm}$ above the coastal levels along the eastern shore of the bay (Tseng et al., 2012).

The potential energy of this dome with respect to the coast can be estimated by assuming the dome has a cosinebell profile from the center with $\lambda / 2 \approx 30 \mathrm{~km}$. Taking the 


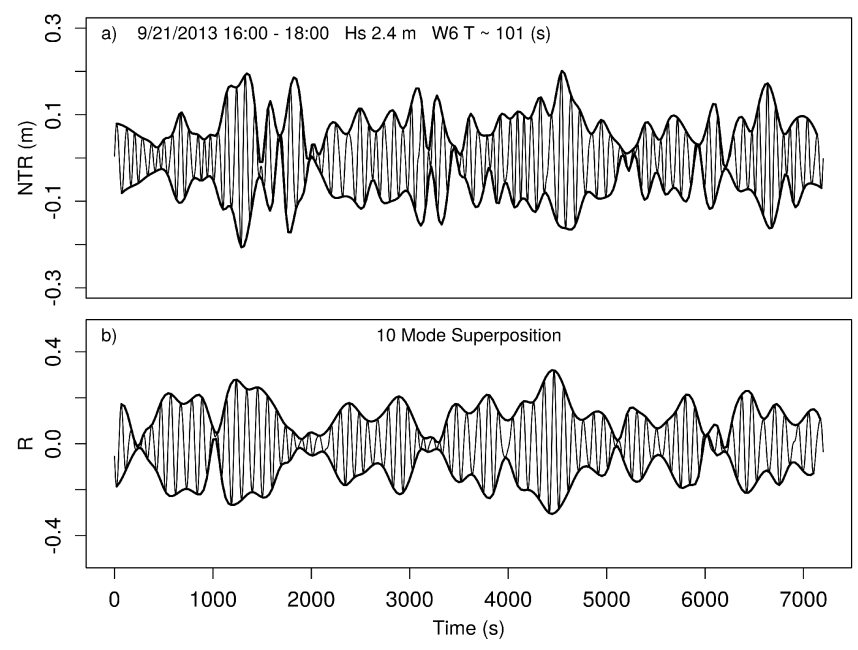

Figure 11. (a) Wavelet level $\mathrm{W}_{6}$ of the nontide residual over a $2 \mathrm{~h}$ period on 21 September 2013 when offshore wave height was $2.4 \mathrm{~m}$. (b) Time series reconstruction from ten spectral amplitudes of Fig. 6 at periods of 58, 83, 94, 97, 100, 104, 107, 112, 116 and $209 \mathrm{~s}$.

height of the dome to be $h_{\mathrm{G}}=10 \mathrm{~cm}$, the dome volume is $V_{\mathrm{G}}=2 \pi \int_{0}^{\lambda / 2}\left[h_{\mathrm{G}} x+h_{\mathrm{G}} x \cos (k x)\right] \mathrm{d} x=168 \mathrm{Mm}^{3}$ where $k=2 \pi / \lambda$. The potential energy of this mass is $E_{\mathrm{G}}=\rho V_{\mathrm{G}} g \frac{h_{\mathrm{G}}}{\sqrt{2}}=120.7 \mathrm{GJ}$, which is comparable with the $115.5 \mathrm{GJ}$ estimated to sustain the $36.7 \mathrm{~min}$ fundamental mode. However, even though the geostrophic balance of the gyre will fluctuate due to wind stress and dynamics of gyre interaction with the California Current, it is unlikely that the geostrophic balance will fluctuate by its full amplitude on timescales of $30 \mathrm{~min}$, allowing this mass of water to relax and propagate as a wave.

The kinetic energy of the equatorward portion of the gyre can be estimated from the cross-sectional flow of the gyre, which from the model of Tseng and Breaker (2007) during a weak flow regime (April) can be represented as a velocity of $u=5 \mathrm{~cm} \mathrm{~s}^{-1}$ from a depth of at least 200 to $600 \mathrm{~m}$ over a width of $30 \mathrm{~km}$. A $30 \mathrm{~km}$ long section of this flow (corresponding to the length of the equatorward portion of the gyre just offshore the bay) would have a kinetic energy of $E_{\mathrm{K}}=\frac{1}{2} \rho V_{\mathrm{K}} u^{2}=465.8 \mathrm{GJ}$, so there appears to be sufficient energy in the jet offshore the bay to sustain the fundamental mode, but it is not clear how a portion of this energy would couple into the mode.

One possibility is that the shear interface between the jet and deeper water generates Kelvin-Helmholtz instabilities to drive the fundamental mode. With the assumption of two stratified water masses of density $\rho_{1}$ and $\rho_{2}$ and mean velocities $U_{1}$ and $U_{2}$, the minimum horizontal wave number of instabilities can be found from a dispersion relation of the unsteady Bernoulli equation (Kundu, 1990) as

$k_{\min }<\frac{g\left(\rho_{2}^{2}-\rho_{1}^{2}\right)}{\rho_{1} \rho_{2}\left(U_{2}-U_{1}\right)^{2}}$.

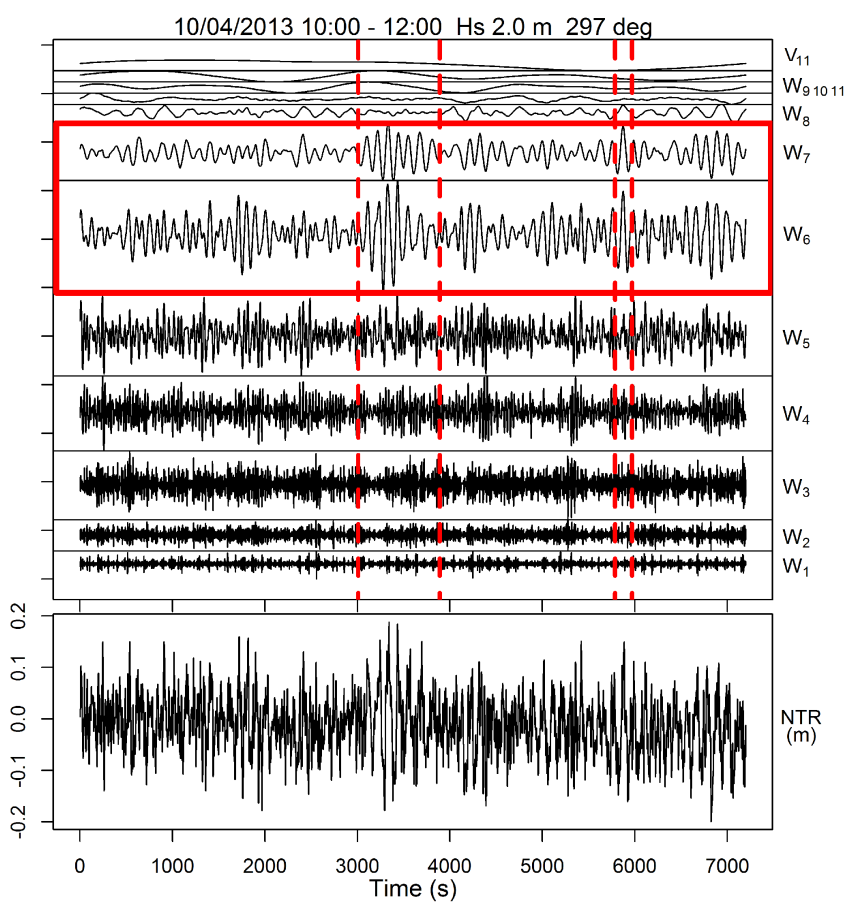

Figure 12. Discrete wavelet transform decomposition of nontide residual water level during a $2 \mathrm{~h}$ period with an offshore significant wave height of $2.0 \mathrm{~m}$. Dashed vertical lines mark periods of synchronization between the $\mathrm{W}_{7}(T \approx 118 \mathrm{~s})$ and $\mathrm{W}_{6}(T \approx 111 \mathrm{~s})$ levels.

To apply this, we assume that the upper water mass is the warmer, fresher water of the California Current gyre $\left(\rho_{1}, U_{1}\right)$ and the lower layer the colder, saltier deep water $\left(\rho_{2}, U_{2}\right)$, where values of $\rho_{1}=1026.70 \mathrm{~kg} \mathrm{~m}^{-3}$ and $\rho_{2}=$ $1026.97 \mathrm{~kg} \mathrm{~m}^{-3}$ are mean values from the surface to a depth of $200 \mathrm{~m}$ at offshore and canyon locations computed from temperature and salinities reported in Fig. 13 of Rosenfeld et al. (1994) using the method of Gill (1982). The resultant maximum wavelengths over the range of velocity differences suggested by Tseng and Breaker (2007) $\left(30-70 \mathrm{~cm} \mathrm{~s}^{-1}\right)$ indicate that instabilities with length scales of several hundred meters are possible. However, these length scales are much shorter than the characteristic scale of the 36.7 min fundamental bay mode $(26.7 \mathrm{~km})$, and it seems unlikely that even coherent trains of such instabilities could effectively drive the fundamental mode.

Finally, we examined whether there was a relation between the seasonal upwelling and mode response. Upwelling in the bay typically peaks in spring/summer (April/May), introducing a tongue of upwelled water between the gyre and the outside edge of the bay. It was assumed that, if the bay modes are driven by the gyre, then upwelling that might partially decouple the bay from the gyre could have an impact on the bay mode amplitudes. We compared PSD estimates of the $6 \mathrm{~min}$ data averaged over 17 years for April and May with PSD estimates from September and October, but found no statistically 

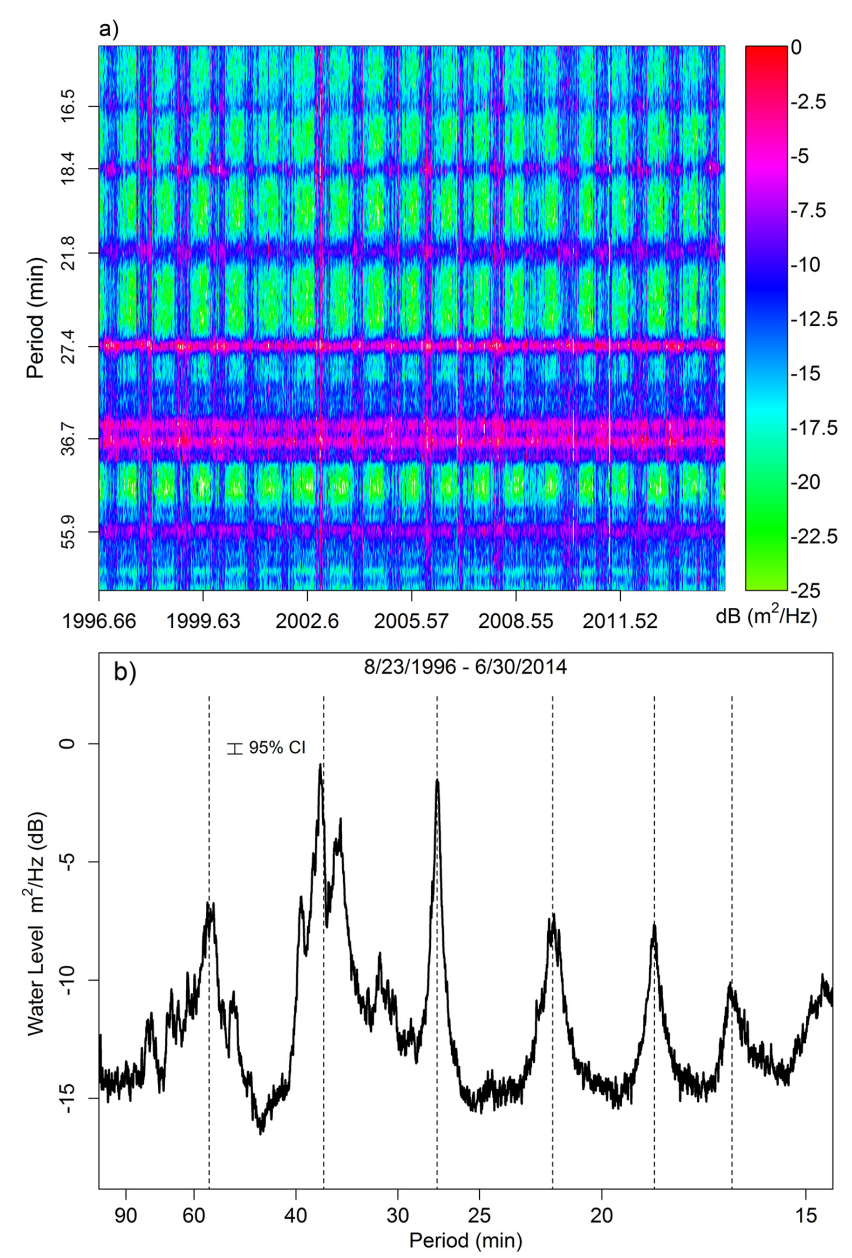

Figure 13. (a) Spectrogram of 6 min water levels at the Monterey tide gauge from August 1996 through June 2014. (b) Power spectral density estimate of $6 \mathrm{~min}$ water levels at the Monterey tide gauge from August 1996 through June 2014. Dashed vertical lines mark the bay-wide resonance modes of 55.9, 36.7, 27.4, 21.8, 18.5 and $16.5 \mathrm{~min}$.

significant differences. To the extent that upwelling was expressed in the April and May data, we find no evidence to support the idea that it changes the oscillating modes.

\section{Conclusions}

Monterey Bay is an intensely studied oceanic body, with the Naval Postgraduate School, Moss Landing Marine Laboratories, Hopkins Marine Station and Monterey Bay Aquarium Research Institute providing decades of physical oceanographic research. Water level oscillations in the bay have been studied since at least the late 1940s, yet it seems that Breaker et al. (2008) were the first to notice that bay-wide oscillations are continuously present. Based on a 17.8 year record of water levels at the NOAA tide station, we substantiate their observation and validate the accuracy of os- cillation periods of the six primary bay modes determined by Breaker et al. (2010). Amplitudes of the bay modes indicate that the fundamental transverse mode $(36.7 \mathrm{~min}$ ) is the mode that is most directly driven by the unknown source. Kinematics of this oscillation coupled with the resonance amplitude lead us to estimate that a power source of roughly $52.4 \mathrm{MW}$ drives this mode. Comparison of this energy rate to prospective forcings from microseisms, internal waves and the associated turbulence indicate that neither of these mechanisms has sufficient power to sustain the mode. We also find that surface waves are not coherently related to the bay modes.

A potential mode driver is the anticyclonic mesoscale gyre situated just offshore the bay. The potential and kinetic energy it contains are sufficient to sustain the fundamental mode; however, we find that turbulent instabilities such as Kelvin-Helmholtz waves generated in the shear interface of the gyre do not have spatial scales consistent with the fundamental mode. It is intriguing to note that the nodal line of the fundamental transverse mode would be located roughly $\lambda / 2=26.7 \mathrm{~km}$ from the eastern shore, corresponding roughly to the eastern edge of the gyre. It would seem a peculiar circumstance if this spatial arrangement along with the potential and kinetic energy scales of the gyre were merely coincidental to the continuous harmonic driver of bay modes, but presently we cannot conceptualize a supportable mechanism for such a coupling. While the present study is purely observational, high-resolution non-hydrostatic coupled ocean-atmosphere models could clarify the roles of potential mode drivers, and should be pursued.

Regarding oscillations in Monterey Harbor, we present the first high-resolution analysis resolving spectral components to periods as short as $2 \mathrm{~s}$. The spectral nature of these modes indicates that they represent a continuum of harmonic oscillators closely spaced in wave number. For example, the $112 \mathrm{~s}$ dominant mode can be attributed to standing waves between the tide gauge and multiple boundaries including the rocky coast to the east, the breakwater to the north and mooring docks to the northeast, while the $41 \mathrm{~s}$ mode is associated with the breakwater to the south. Concerning wave forcing, it is demonstrated that the primary harbor mode amplitude grows as the square root of offshore significant wave height, and that there is a mode-specific dependence on wave-arrival direction. It is also observed that tidal phase serves to frequency modulate the harbor modes, with evidence of enhanced mode energy during high tide.

A temporal analysis monitoring the evolution of harbor modes in response to wave forcing supports the idea that amplitude modulation of specific harbor modes arises from modal interference, and it is observed that when such modulations synchronize, they can have a significant impact on water level amplitude. Identification of specific modes with associated physical sources raises the possibility of engineering solutions to mitigate specific oscillations. 


\section{Appendix A}

The maximal overlap discrete wavelet transform (MODWT, Percival and Walden, 2006) is defined by

$\boldsymbol{X}=\sum_{j}^{J} \boldsymbol{D}_{j}+\boldsymbol{S}_{J}$,

where $\boldsymbol{X}$ is a time series of length $N$ and $j$ represents a distinct wavelet level. The $\boldsymbol{D}_{j}$ are referred to as wavelet details, and $S_{J}$ the smooth, each a vector of length $N$. The details capture transient and oscillatory behavior at different timescales; the smooth are the residual energy not captured by the details and, in the optimal decomposition, correspond to a moving average of the signal. Each wavelet level is computed with a matrix transform $\boldsymbol{D}_{j}=\mathbf{W}_{j}^{T} \boldsymbol{\Phi}_{j}$ and $\boldsymbol{S}_{J}=$ $\mathbf{V}_{j}^{T} \boldsymbol{\Psi}_{J}$ where $\mathbf{W}$ and $\mathbf{V}$ are $N \times N$ matrices of MODWT coefficients, and $\boldsymbol{\Phi}$ and $\boldsymbol{\Psi}$ are referred to as the wavelet coefficient and scaling coefficient vectors, respectively. The wavelet and scaling coefficients are the result of cascaded high-pass $(h)$ or low-pass $(g)$ wavelet and scaling filters recursively applied to the input $\boldsymbol{\Phi}_{j, t}=\sum_{l-0}^{L_{j}-1} h_{j, l} \boldsymbol{X}_{t-1, \bmod N}$, or $\boldsymbol{\Psi}_{j, t}=\sum_{l-0}^{L_{j}-1} g_{j, l} \boldsymbol{X}_{t-1, \bmod N}$, where the filter width at each level $L_{j}=\left(2^{j}-1\right)(L-1)+1$ is determined by the length of the mother wavelet L. In terms of the MODWT matrix and wavelet scaling coefficients, the input can then be represented as

$\boldsymbol{X}=\sum_{j}^{J} \mathbf{W}_{j}^{T} \boldsymbol{\Phi}_{j}+\mathbf{V}_{J}^{T} \boldsymbol{\Psi}_{J}$.

The MODWT provides a convenient encapsulation of the signal energy in terms of the wavelet and scaling coefficient vectors:

$\|\boldsymbol{X}\|^{2}=\sum_{j}^{J}\left\|\boldsymbol{\Phi}_{j}\right\|^{2}+\left\|\boldsymbol{\Psi}_{J}\right\|^{2}$,

which is related to the sample variance of $\boldsymbol{X}$. It is useful to plot the wavelet coefficients of each level scaled by its respective magnitude squared so that the relative amplitude scales represent the partial variance contributed by each level. 
Acknowledgements. The authors gratefully acknowledge insightful discussions and reviews of the manuscript by L. Breaker of Moss Landing Marine Laboratory, University of California, and Y.-H. Tseng, National Center for Atmospheric Research (NCAR) Earth Systems Laboratory.

Edited by: E. J. M. Delhez

\section{References}

AMS: Seiches in Lake Garda, Mon. Weather Rev., 31, 532-533, doi:10.1175/1520-0493(1903)31[532b:SILG]2.0.CO;2, 1903.

AMS: The seiche and its mechanical explanation, Mon. Weather Rev., 34, 226, doi:10.1175/15200493(1906)34<226b:TSAIME>2.0.CO;2, 1906.

Bloomfield, P.: Fourier Analysis of Time Series: An Introduction, Wiley, New York, 1st Edn., 261 pp., 1976.

Breaker, L. C., Broenkow, W. W., Watson, W. E., and Jo, Y.: Tidal and non-tidal oscillations in Elhorn Slough, California, Estuar. Coast., 31, 239-257, 2008.

Breaker, L. C., Tseng, Y., and Wang, X.: On the natural oscillations of Monterey Bay: observations, modeling, and origins, Prog. Oceanogr., 86, 380-395, doi:10.1016/j.pocean.2010.06.001, 2010.

Bromirski, P. D. and Duennebier, F. K.: The near-coastal microseism spectrum: spatial and temporal wave climate relationships, J. Geophys. Res.-Sol. Ea., 107, ESE 5-1-ESE 5-20, doi:10.1029/2001JB000265, 2002.

Carter, G. S. and Gregg, M. C.: Intense, variable mixing near the head of Monterey Submarine Canyon, J. Phys. Oceanogr., 32, 3145-3165, doi:10.1175/15200485(2002)032<3145:IVMNTH>2.0.CO;2, 2002.

CDIP: Station 156 Monterey Canyon Outer, available at: $\quad$ http://cdip.ucsd.edu/?nav=recent\&stn=156\&sub= observed \&xitem $=$ info\&stream $=\mathrm{p} 1$, last access: 14 November 2014.

Chrystal, G.: On the hydrodynamical theory of seiches, T. Roy. Soc. Edin.-Earth, 41, 599-649, doi:10.1017/S0080456800035523, 1906.

Darwin, G. H.: The Tides and Kindred Phenomena in the Solar System, Houghton, Boston, 342 pp., 1899.

Forston, E. P., Brown, F. R., Hudson, R. Y., Wilson, H. B., and Bell, H. A.: Wave and surge action, Monterey Harbor, Monterey California, Tech. Rep. 2-301, United States Army Corps of Engineers, Waterways Experiment Station, Vicksburg, MS, 45 Plates, 1949.

Gill, A. E.: Atmosphere-Ocean Dynamics, Academic Press, New York, 662 pp., 1982.

Hasselmann, K.: A statistical analysis of the generation of microseisms, Rev. Geophys., 1, 177-210, doi:10.1029/RG001i002p00177, 1963.

IOOS: A National Operational Wave Observation Plan. Integrated Ocean Observing System (IOOS) plan for a surfacewave monitoring network for the United States, Tech. rep., Integrated Ocean Observing System, available at: http://www.ioos. noaa.gov/library/wave_plan_final_03122009.pdf (last access: 14 November 2014), 2009.
Kedar, S., Longuet-Higgins, M., Webb, F., Graham, N., Clayton, R., and Jones, C.: The origin of deep ocean microseisms in the North Atlantic Ocean, P. R. Soc. A, 464, 777-793, doi:10.1098/rspa.2007.0277, 2008.

Key, S. A.: Internal tidal bores in the Monterey Canyon, M. S. thesis, Naval Postgraduate School, available at: http://www.dtic.mil/ dtic/tr/fulltext/u2/a370949.pdf (last access; 14 November 2014), 1999.

Kundu, P. K.: Fluid Mechanics, Academic Press, San Diego, 1st Edn., 638 pp., 1990.

Kunze, E., Rosenfeld, L. K., Carter, G. S., and Gregg, M. C.: Internal waves in Monterey Submarine Canyon, J. Phys. Oceanogr., 32, 1890-1913, doi:10.1175/15200485(2002)032<1890:IWIMSC>2.0.CO;2, 2002.

NOAA: Monterey, CA, National Water Level Observation Network - Station ID: 9413450, available at: http://tidesandcurrents. noaa.gov/stationhome.html?id=9413450, last access: 14 November 2014a.

NOAA: Harmonic Constituents for 9413450, Monterey CA, available at: http://tidesandcurrents.noaa.gov/harcon.html?id= 9413450, last access: 14 November 2014b.

Park, J., Heitsenrether, R., and Sweet, W.: Microwave and acoustic water level and significant wave height estimates at NOAA tide stations, J. Atmos. Ocean. Tech., 31, 2294-2308, 2014.

Parke, M. E. and Gill, S. K.: On the sea state dependence of sea level measurements at platform Harvest, Mar. Geod., 18, 105111, 1995.

Percival, D. B. and Walden, A. T.: Wavelet Methods for Time Series Analysis, Cambridge University Press, New York, 594 pp., 2006.

Petruncio, E., Rosenfeld, L., and Paduan, P.: Observations of the internal tide in Monterey Canyon, J. Phys. Oceanogr., 28, 1873-1903, doi:10.1175/15200485(1998)028<1873:OOTITI>2.0.CO;2, 1998.

Raines, W. A.: Sub-tidal oscillations in Monterey Harbor, M.S. thesis, Naval Postgraduate School, available at: https://calhoun.nps.edu/bitstream/handle/10945/13214/ subtidaloscillat00bain.pdf?sequence $=1$ (last access: 4 June 2015), 1967.

Rosenfeld, L. K., Schwing, F. B., Garfield, N., and Tracy, D. E.: Bifurcated flow from an upwelling center: a cold water source for Monterey Bay, Cont. Shelf. Res., 14, 931-964, doi:10.1016/0278-4343(94)90058-2, 1994.

Shchepetkin, A. F. and McWilliams, J. C.: The regional oceanic modeling system (ROMS): a split-explicit, free-surface, topography-following-coordinate oceanic model, Ocean Model., 9, 347-404, doi:10.1016/j.ocemod.2004.08.002, 2005.

Ryan, J. P., Davis, C. O., Tufillaro, N. B., Kudela, R. M. and Gao, B. C.: Application of the Hyperspectral Imager for the Coastal Ocean to Phytoplankton Ecology Studies in Monterey Bay, CA, USA, Remote Sens., 6, 1007-1025, doi:10.3390/rs6021007, 2014.

Strub, P. T., Kosro, P. M., and Huyer, A.: The nature of the cold filaments in the California Current system, J. Geophys. Res.Oceans, 96, 14743-14768, doi:10.1029/91JC01024, 1991.

Tseng, Y.-H. and Breaker, L. C.: Nonhydrostatic simulations of the regional circulation in the Monterey Bay area, J. Geophys. Res.Oceans, 112, C12017, doi:10.1029/2007JC004093, 2007.

Tseng, Y.-H., Dietrich, D. E., and Ferziger, J. H.: Regional circulation of the Monterey Bay region: hydrostatic versus non- 
hydrostatic modeling, J. Geophys. Res.-Oceans, 110, C09015, doi:10.1029/2003JC002153, 2005.

Tseng, Y.-H., Chien, S.-H., Jin, J., and Miller, N. L.: Modeling airland-sea interactions using the integrated regional model system in Monterey Bay, California, Mon. Weather Rev., 140, 12851306, doi:10.1175/MWR-D-10-05071.1, 2012.

Waxler, R. and Gilbert, K. E.: The radiation of atmospheric microbaroms by ocean waves, J. Acoust. Soc. Am., 119, 2651-2664, doi:10.1121/1.2191607, 2006.
Webb, S. C. and Cox, C. S.: Observations and modeling of seafloor microseisms, J. Geophys. Res.-Sol. Ea., 91, 7343-7358, doi:10.1029/JB091iB07p07343, 1986.

Wilson, B. W., Hendrickson, J. A., and Kilmer, R. E.: Feasibility study for a surge-action model of Monterey Harbor, California, Tech. Rep. 2-136, United States Army Corps of Engineers, Waterways Experiment Station, Vicksburg, MS, 1965. 